\title{
Design and Simulation of Active Filter Circuit Based on OP275
}

\author{
Ke Zhang* \\ Chengdu Aeronautic Polytechnic, Chengdu, Sichuan, China \\ ${ }^{*}$ Corresponding author
}

\begin{abstract}
In order to reduce the simulation sampling noise preamplifier, the authors used the integrated operational amplifier are designed respectively low-pass filter, high pass filter and band-pass filter circuit three circuit, and Multisim 12 software was used for each of these circuit simulation and analysis of the circuit of the indicators and characteristics.
\end{abstract}

Keywords-operational amplifier; Multisim 12; simulation; OP275; filter

\section{INTRODUCTION}

An operational amplifier (abbreviated as "op amp") is a circuit unit with a high magnification. In the actual circuit, a functional module is usually combined with the feedback network. Because of the early application to the analog computer to realize the mathematical operation, it is named "operational amplifier". An op amp is a circuit unit named from a functional point of view, which can be realized by a discrete device or in a semiconductor chip. With the development of semiconductor technology, most of the op amp is in the form of single chip . There are many kinds of OP[1] and AMP, which are widely used in the electronics industry.

At present in many fields such as environmental protection industry[2], we need to use sensors to collect signal, the weak signal is amplified after sent to circuit for processing, in this process will introduce all kinds of factors on noise in useful frequency band outside, in order to make the circuit processes the signal more accurately and make judgments, we the need to introduce filter in the circuit to ensure the signal of "clean", the useless signal blocked in the door". The use of integrated operational amplifiers[3] as the core of the filter is a low-cost and effective solution.

The simulation is carried out by national instrument produced by Multisim 12 simulation software based on OP275 chip design of filter circuit, and has made the corresponding analysis, which can greatly improve the efficiency of circuit design, convenient design performance is more sophisticated and reliable circuit.

\section{LOW PASS FILTER DESIGNED By OP275}

In Multisim 12 draw low-pass filter circuit as the cut-off frequency is shown in Figure I using OP275 design for $2.75 \mathrm{kHz}$.

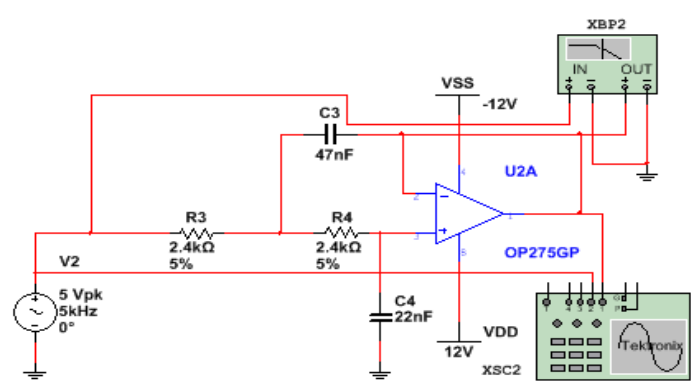

FIGURE I. OP275 LOW PASS FILTER DESIGN CIRCUIT

In Multisim 12 draw as a low pass filter circuit designed by OP275 is shown in Figure I, the power of positive and negative $12 \mathrm{~V}$ power supply, the cut-off frequency of the designed filter is $2.75 \mathrm{kHz}$, the input signal is the peak value of $5 \mathrm{~V}$, frequency of $5 \mathrm{kHz}$, start switch circuit simulation circuit simulation measurement, through the oscilloscope to observe what output results:

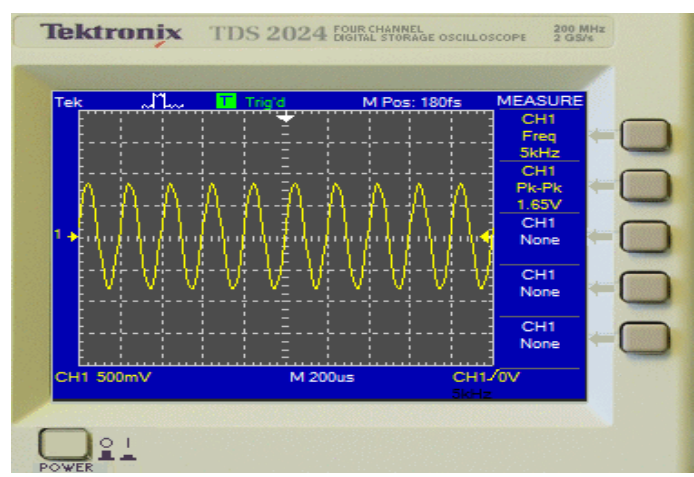

FIGURE II. OP275 LOW PASS FILTER DESIGN CIRCUIT USING THE TEK OSCILLOSCOPE SIMULATION TEST RESULTS

From the simulation results above the author can see, the input signal source for the $5 \mathrm{kHz}$, the author is greater than the cutoff frequency of the $2.75 \mathrm{kHz}$ signal appeared obvious attenuation, seen in the Tektronix oscilloscope as the peak to peak value on the $1.65 \mathrm{~V}$, the value of that band signal has been well suppressed by low pass filter and meet the design requirements. Then analyze and observe the simulation results of Potter diagram. 


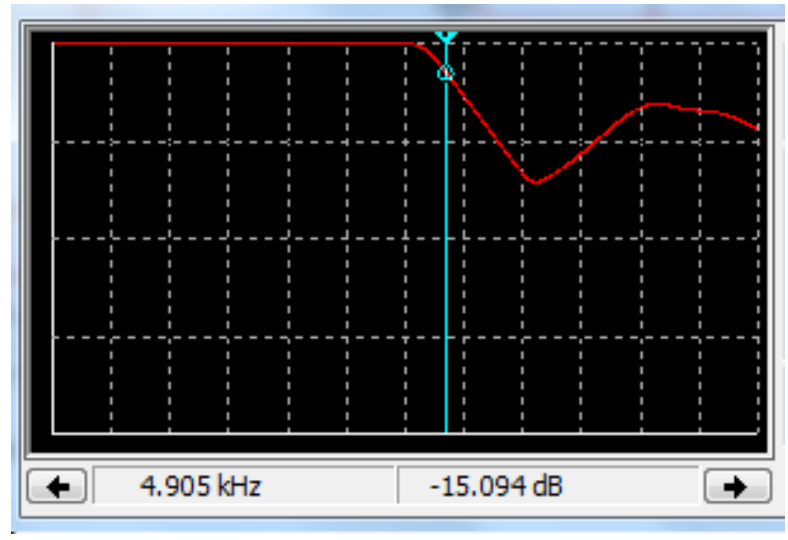

FIGURE III. OP275 LOW PASS FILTER DESIGN CIRCUIT POTTER DIAGRAM SIMULATION TEST RESULT

In the Potter diagram of Figure III, the author chooses the relationship between amplitude and frequency characteristics to simulate, and start the circuit simulation switch to carry out circuit simulation and measurement. From the simulation data, the author can see that, when $4.905 \mathrm{kHz}$, OP275 attenuates the signal to $-15.094 \mathrm{~dB}$. The following table is the attenuation of signals with OP275 at different frequencies:

TABLE I. SIMULATION TEST RESULTS OF THE LOW PASS FILTER OF 2.75KHZ DESIGNED BY OP275 IN THE POTTER DIAGRAM

\begin{tabular}{|c|l|l|l|l|}
\hline $\begin{array}{c}\text { Signal } \\
\text { frequency } \\
\text { (Hz) }\end{array}$ & 101.67 & $4.905 \mathrm{k}$ & $159.015 \mathrm{k}$ & $16.991 \mathrm{M}$ \\
\hline $\begin{array}{c}\text { Decrement } \\
\text { (-dB) }\end{array}$ & 0.001 & 15.094 & 71.304 & 31.117 \\
\hline
\end{tabular}

See from the data in Table I, when the frequency is lower than $2.75 \mathrm{kHz}$, OP275 low pass filter design for signal almost no attenuation, such as at the time of $101.67 \mathrm{~Hz}$, the signal attenuation is $0.001 \mathrm{~dB}$; when the signal frequency is less than $2.75 \mathrm{kHz}$, the circuit of signal attenuation in the frequency band of $-6 \mathrm{~dB}$, a small signal attenuation, and designed by the author is very close to the theoretical value. When the signal frequency is greater than $2.75 \mathrm{kHz}$, the attenuation is very large outside the band. For example, when the signal is at $159.015 \mathrm{kHz}$, the attenuation outside the band reaches the maximum value of $-71.304 \mathrm{~dB}$. The authors also observed that when the signal frequency is greater than $16.991 \mathrm{MHz}$, the signal will produce $31.117 \mathrm{~dB}$ attenuation, which is somewhat larger than the maximum attenuation value. This is because the actual operational amplifier will be limited by the maximum working frequency of the device.

\section{High PASS FILTER DESIGNED By OP275}

In Multisim12, a high pass filter circuit designed by OP275, as shown in Figure IV, is shown in Figure IV.

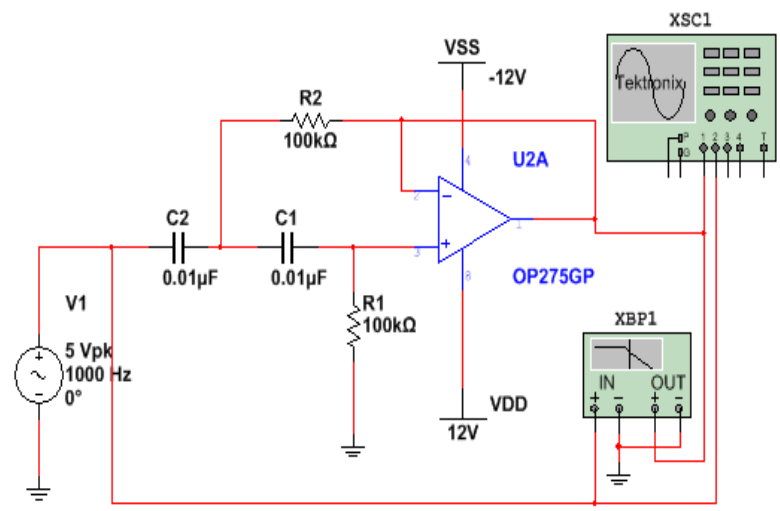

FIGURE IV. OP275 HIGH PASS FILTER DESIGN CIRCUIT

Draw as shown in Figure IV for the design of OP275 high pass filter circuit in Multisim12 power supply, 12V power supply by positive, the cut-off frequency of the designed filter is $160 \mathrm{~Hz}$, the input signal is the peak value of $5 \mathrm{~V}$, frequency of $1 \mathrm{kHz}$, start switch circuit simulation circuit simulation measurement, the authors examine the output results through the oscilloscope:

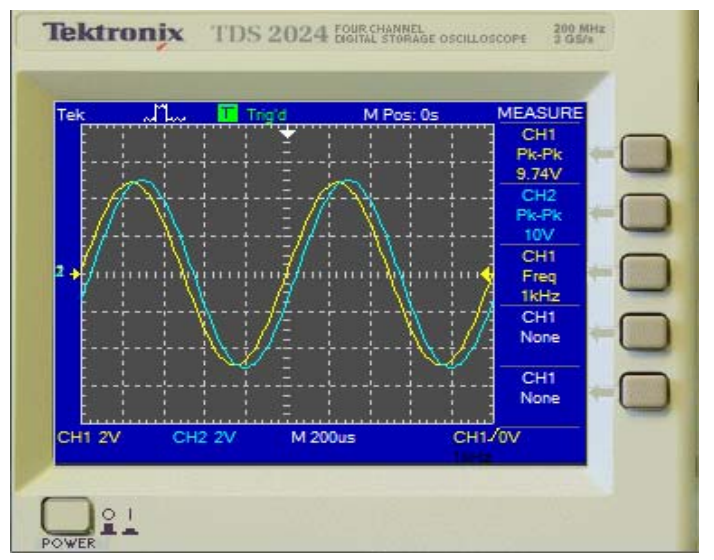

FIGURE V. OP275 HIGH PASS FILTER DESIGN CIRCUIT USING THE TEK OSCILLOSCOPE SIMULATION TEST RESULTS

From the simulation results above the author can see, because the signal input excitation source for $1 \mathrm{kHz}$, the cut-off frequency of $160 \mathrm{~Hz}$ is greater than the author, so when the excitation signal through high pass filter designed by $160 \mathrm{~Hz}$, a signal attenuation decreased from $10 \mathrm{~V}$ Pk-Pk to $9.74 \mathrm{Pk}-\mathrm{Pk}$. This value is within the scope of the theory, and the author will also analyze the results of the simulation of the Potter diagram. 


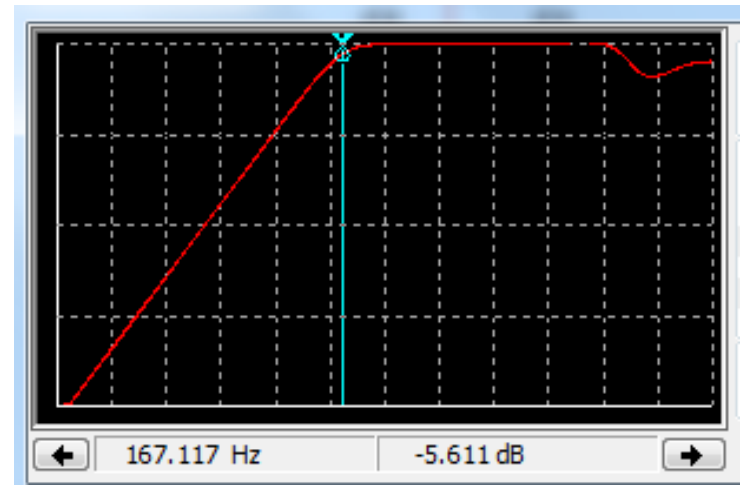

FIGURE VI. OP275 HIGH PASS FILTER DESIGN CIRCUIT POTTER DIAGRAM SIMULATION TEST RESULT

In Figure VI the figure of Potter, the author chose the relationship between the amplitude frequency characteristic simulation, start switch circuit simulation circuit simulation measurement, the author from the simulation data can be seen at the time of $167.117 \mathrm{~Hz}, \mathrm{OP} 275$ reached $-5.611 \mathrm{~dB}$ on signal attenuation, the author set close to the theoretical value with value is $(160 \mathrm{~Hz}$ the table below), $-6 \mathrm{~dB}$ attenuation is 2 at different frequencies with OP275 on signal attenuation:

TABLE II. SIMULATION TEST RESULTS OF THE HIGH PASS FILTER OF 160HZ DESIGNED BY OP275 IN THE POTTER DIAGRAM

\begin{tabular}{|c|l|l|l|l|}
\hline $\begin{array}{c}\text { Signal } \\
\text { frequency } \\
\text { (Hz) }\end{array}$ & 50.703 & 167.117 & $10.864 \mathrm{k}$ & $22.894 \mathrm{M}$ \\
\hline $\begin{array}{c}\text { Decrement } \\
\text { (-dB) }\end{array}$ & 20.711 & 5.611 & 0.015 & 6.517 \\
\hline
\end{tabular}

See Table II data from the author, when the frequency is lower than $160 \mathrm{~Hz}$, OP275 high pass filter design for signal attenuation, such as at the time of $50.703 \mathrm{~Hz}$, the frequency attenuation reached $-20.711 \mathrm{~dB}$; when the signal frequency is greater than $160 \mathrm{~Hz}$ and less than $22.894 \mathrm{MHz}$, the circuit of signal attenuation in the pass band in $-6 \mathrm{~dB}$ very small, the signal attenuation, and designed by the author is very close to the theoretical value, such as signal at the time of $10.864 \mathrm{kHz}$, pass band attenuation is only $-0.015 \mathrm{~dB}$, and the author also see in the simulation test results of Potter graphic instrument, the circuit designed by OP275 is very flat in the pass band, close to the ideal value. The author also observed that when the frequency of the signal is greater than $22.894 \mathrm{MHz}$, the signal produces a large attenuation and a relatively stable attenuation at a larger frequency. This is because the actual device has a maximum working frequency, and the circuit parameters of the device will fail when it is larger than the working frequency. From the result of this simulation, the actual bandwidth of OP275 has reached the level of $22 \mathrm{MHz}$, and it is already a very excellent device.

\section{BANDPAss Filter Designed By OP275}

The design of bandpass filter only needs to connect the output of the high pass filter to the input end of the low pass filter to form a bandpass filter. After Multisim12 simulation, we can get the following filter data:
TABLE III. THE SIMULATION TEST RESULTS OF A BAND PASS FILTER WITH BANDWIDTH OF 160HZ-2.75KHZ IN POTTER DIAGRAM IN OP275

\begin{tabular}{|c|l|l|l|l|}
\hline $\begin{array}{c}\text { Signal } \\
\text { frequency } \\
\text { (Hz) }\end{array}$ & 50.703 & 151.306 & $2.702 \mathrm{k}$ & $21.784 \mathrm{k}$ \\
\hline $\begin{array}{c}\text { Decrement } \\
\text { (-dB) }\end{array}$ & 20.711 & 6.471 & 5.761 & 40.968 \\
\hline
\end{tabular}

From the data on the table, it can be seen that the signal in the design passband attenuates within $6 \mathrm{~dB}$ to meet the design requirements.

\section{CONCLUSIONS}

In this paper, a low pass, high pass and bandpass filter circuit is designed with OP275 chip, and the circuit is simulated with the Multisim 12[4] software produced by national instruments.. Now with more and more electronic products [5], the application of operational amplifier is more and more widely, with operational amplifier filter design is helpful to improve the signal-to-noise ratio of the circuit, and low cost, low cost greatly improve the circuit performance, this amplifier in environmental protection equipment for the operation of new energy equipment the application of audio equipment, the player opens a broad market.

\section{ACKNOWLEDGMENT}

This work supported by Sichuan Provincial Education Office natural science scientific research fund project P.R.China Grant No. 17ZB0042.

\section{REFERENCES}

[1] Jiang Tao, The design and application of medical bioelectrical signal amplifier. Laboratory medicine and clinic. 2010.2 Vol.7 No.4

[2] Zhang Ke, Design and implementation of a Band-Gap reference voltage source based on LDO. Chengdu Southwest Jiao Tong University. 2006

[3] Liang Tinggui, Zhou Haomiao. Research on the analysis method of integrated operational amplifier linear application circuit [J]. journal of tangshan college, 2009, 22 (6): 86-89

[4] Zeng Wei, Integrated operational amplifier based on Multisim10. Electronics and encapsulation 2011.12

[5] Li Zheying, Locke, Li Jinping. Analogue electronic circuit analysis and Multisim simulation [M]. Beijing: Machinery Industry Press, 2008. 